\title{
Tobacco Consumption among High School Adolescents
}

Yadu Ram Upreti*

\begin{abstract}
This article highlights the practice of tobacco consumption among high school adolescents of Hariwan municipality, a growing semi-urban area of Sarlahi district in Nepal. The study utilized descriptive cross-sectional survey research design with quantitative method to get the required information to the study. Four high schools (two community and two private schools) were randomly sampled to select the respondents. In total, 224 adolescents ( $n=224$ ) aged 15 to 19 years studying in grade eleven and twelve were selected. A set of pretested self-administered questionnaire was employed to collect the required information. Before data were collected, verbal consent was obtained from the authority of schools and respondents themselves. Only self-reported primary nature of data were utilized to obtain answers to the research questions. Data were entered and analyzed using SPSS software with 16.0 versions. Chi-square test and $t$-test of bivariate analysis were used to analyze the results. The study revealed that around one-fourth (22.8\%) of high school adolescents consumed at least one type of tobacco products. Cigarette was the most common tobacco product among the youth followed by Panparag and Gutkha. Most of them consumed tobacco for entertainment followed by experimentation. Various factors are associated with the consumption of tobacco amongst which peer pressure, parental and relatives' influence, and media exposure remain significant ones. Monitoring high-risk behaviors, announcing tobacco-free public places, making aware towards glamorized tobacco promotional pro-active advertisements, etc. will be effective to minimize the tobacco consumption practice among in-school youths.
\end{abstract}

Keywords: adolescents, experimentation, health promotion, high school, tobacco consumption, peer pressure

\section{Background}

Adolescence is a fundamental stage of growth and development during which boys and girls move from childhood to adulthood being physically, mentally, socially, and emotionally matured. Boys and girls of 10-19 years of age are considered as adolescents (WHO, 2004). As adolescents get matured cognitively, their mental process becomes more analytical due to which they tend to be capable of Abstract thinking, better articulation and of developing an independent ideology (ibid). Adolescence is truly the time of creativity, idealism, optimism and a spirit of adventure. However, it is also the period of experimentation, risk-taking to negative behaviours, peer pressure, and taking uninformed decisions on crucial issues, especially relating to their bodies and their sexuality. Adolescence is, thus, a turning point in one's life, a period of increased potential; but it is also the time of greater susceptibility to risk, associated bad health habit and sexual behaviors. As it is very active period of life, seeking of new experiences and learning many things take place in this period. Tobacco consumption has become one of the risky health behaviours among adolescents (WHO, 2014)

Smoking is a risk factor for cardiovascular disease, lung cancer, and other forms of cancer, and it contributes to the severity of pneumonia, emphysema, and chronic bronchitis symptoms. Also, second hand smoke may adversely affect the health of children, adolescents and aggravate many illnesses. Smoking-attributed diseases include cancer of trachea, lung, bronchus, lip, mouth and pharynx, ischemic heart disease, stroke, hypertension, bronchitis, chronic obstructive pulmonary disease, emphysema and asthma (Green, 2002). McKenzie, Pinger, \& Kotecki (2005) stated:

".....smokes released from burnt tobacco consists of more than 4 thousand numbers of vaporized chemical carcinogenic and non-carcinogenic substances. Some of the active ingredients of cigarettes are: Tar,

* Lecturer, Health and Population Education Department, TU, Kirtpur 
Nicotine, Carbon monoxide, Ammonia, Carbonate, Cadmium, Arsenic, Nitrate, Acetone, Methanol, Hydrogen Cyanide, Hexamine, etc. Tar is a complex mixture of compounds, including 69 identifiable carcinogens and co- carcinogens. Nicotine is the principal constituent responsible for a smoker's pharmacological response (addiction). Smoking and use of other forms of tobacco can cause a wide variety of diseases and can even lead to death". (p. 365)

There is a robust evidence base for the negative health effects from smoking. Smoking is linked with severe morbidity and mortality since it kills up to half of its regular users (Nilsson, 2009 as cited in Green, 2002). Tobacco use among school children is becoming a serious problem in developing countries (WHO, 2014). The early age of initiation underscores the urgent need to intervene and protect this vulnerable group from falling prey to this addiction. The risks of tobacco use are highest among those who start early and continue its use for a long period (Sinha, 2002).

Tobacco use is a major proven risk factor and it contributes substantially to the rising epidemic of non-communicable diseases in the world (Clements \& Rivera, 2013). In the context of Nepal, however, people in the age group of 15-49 years are found active in smoking, adolescents of 15- 19 years age group only accounts 16 percent and this prevalence rate has been in the ratio of increasing trend (Ministry of Health[MoH]; New ERA; and ICF, 2017). The studies undertaken in similar topic state that the initiation of tobacco consumption is around the age of 15 years which falls under the age of adolescents (Clements \& Rivera, 2013; Cleveland, Wiebe \& Rowe, 2017; NDHS, 2011; WHO, 2014). Realizing this fact, the researcher aimed to explore the recent tobacco consumption practice among high school adolescents of semi-urban Terai region of Nepal. And thus, research related problem is stated in the form of questions such as: What is the prevalence of tobacco consumption practice among schooling adolescents? What are the influencing factors for tobacco consumption among adolescents?

\section{Methods}

This study utilized descriptive cross-sectional survey design of quantitative research. Only self-reported primary source of data were used to draw out the inferences of the study. Altogether, four community and five private high schools were there in study area. Hence, the students studying in those nine schools were the total study population. Two community schools out of four and two private schools out of five were randomly selected by using the lottery method of simple random probability sampling technique. The researcher planned to select the respondents randomly, but was compelled to apply census method due to poor presence of respondents at the time of data collection. Hence, the total sample size was 224 $(n=224)$.

A set of pretested self-administered questionnaire was used to collect the data required for this study. Verbal consent was obtained from college administration and respondents after explaining the purpose of the study. Anonymity and confidentiality of the information was also maintained by not mentioning their name in the questionnaire. The questionnaire was distributed to the respondents with the help of some volunteer teachers from school. After collecting the data, they were checked, cleaned, edited, coded and analyzed using Statistical Package for Social Science (SPSS) software with 16.0 version. Bivariate inferential statistical tests like Chi-square test and $\mathrm{t}$ - test were used to analyze the results.

\section{Results and Discussion}

\section{Tobacco consumption practice}

The main objective of this study was to explore the tobacco consumption practice of adolescents studying in high school. Table 1 represents the practice of tobacco consumption among high school adolescents. 
Table 1. Tobacco consumption practice among high school adolescents

\begin{tabular}{|c|c|c|c|c|c|c|c|}
\hline \multirow{3}{*}{ Variables } & \multirow{3}{*}{ Descriptions } & \multicolumn{6}{|c|}{ School Type } \\
\hline & & \multicolumn{2}{|c|}{ Community } & \multicolumn{2}{|c|}{ Private } & \multicolumn{2}{|c|}{ Total } \\
\hline & & $\mathrm{N}$ & $\%$ & $\mathrm{~N}$ & $\%$ & $\mathrm{~N}$ & $\%$ \\
\hline $\begin{array}{l}\text { Knowledge on harmful } \\
\text { effects of tobacco Use } \\
(\mathrm{N}=224)\end{array}$ & Yes & 103 & 72.0 & 57 & 70.4 & 160 & 71.4 \\
\hline $\begin{array}{l}\text { Relatives and friends } \\
\text { who consumed tobacco } \\
(\mathrm{N}=224)\end{array}$ & Yes & 99 & 69.2 & 45 & 55.6 & 144 & 64.3 \\
\hline $\begin{array}{l}\text { Use of tobacco } \\
\text { products }(\mathrm{N}=224)\end{array}$ & Yes & 32 & 22.4 & 19 & 23.5 & 51 & 22.8 \\
\hline $\begin{array}{l}\text { Name of tobacco } \\
\text { products }(\mathrm{N}=32)\end{array}$ & $\begin{array}{l}\text { Cigarette } \\
\text { Surti/Khaini } \\
\text { Bidi } \\
\text { Gutkha } \\
\text { Panparag } \\
\text { Chilum }\end{array}$ & $\begin{array}{l}18 \\
5 \\
2 \\
7 \\
10 \\
1\end{array}$ & \begin{tabular}{l|}
41.8 \\
11.6 \\
4.8 \\
16.3 \\
23.2 \\
2.3
\end{tabular} & $\begin{array}{l}14 \\
1 \\
4 \\
1 \\
8 \\
1\end{array}$ & \begin{tabular}{l|l}
48.4 \\
3.4 \\
13.8 \\
3.4 \\
27.6 \\
3.4
\end{tabular} & $\begin{array}{l}32 \\
6 \\
6 \\
8 \\
18 \\
2\end{array}$ & $\begin{array}{l}44.4 \\
8.3 \\
8.3 \\
11.2 \\
25.0 \\
2.8\end{array}$ \\
\hline \multirow{5}{*}{$\begin{array}{l}\text { Frequency of use of } \\
\text { tobacco products }(\mathrm{N}=32)\end{array}$} & Regular Use & 1 & 3.1 & 0 & 0.0 & 1 & 2.0 \\
\hline & Occasional Use & 11 & 34.4 & 2 & 10.5 & 13 & 25.5 \\
\hline & Use in Special Function & 8 & 25.0 & 5 & 26.3 & 13 & 25.5 \\
\hline & Only to Taste & 12 & 37.5 & 12 & 63.2 & 24 & 47.1 \\
\hline & $<10$ years & 1 & 3.1 & 3 & 15.8 & 4 & 7.8 \\
\hline \multirow{2}{*}{$\begin{array}{l}\text { First age to consuming } \\
\text { tobacco products }(\mathrm{N}=32)\end{array}$} & $10-15$ years & 20 & 62.5 & 10 & 52.6 & 30 & 58.8 \\
\hline & $>15$ years & 11 & 34.4 & 6 & 31.6 & 17 & 33.3 \\
\hline Effort to quit tobacco $(\mathrm{N}=32)$ & Yes & 25 & 78.1 & 13 & 68.4 & 38 & 74.5 \\
\hline
\end{tabular}

Table 1 depicts that 71.4 percent respondents of the total had knowledge on harmful effects of tobacco consumption. However, community school students had a bit higher knowledge $(72 \%)$ than those of private $(70.4 \%)$, chisquare test shows no significant difference (chivalue $=0.070, \mathrm{df}=1$ and $\mathrm{p}$ value $0.878>0.05$ ) between the type of school and knowledge on harmful effect of tobacco use. Further, it can also be discussed that male respondents had better knowledge than those of female students. Similarly, grade eleven, joint family living, Hindu respondents had better knowledge (not shown in the table) than those of their counterpart.

Further, above table also reveals that 69.2 percent respondents' relatives and friends from community school consumed tobacco compared to 55.6 percent from private.

Statistically, there is significant difference (Chi value $=4.21, \mathrm{df}=1, \mathrm{p}$ value $0.043<0.05$ ) between the type of school and the relatives and friends of respondents who consumed tobacco. According to Mujis (2004), this association has modest relationship (chi value $=0.137$ which lies between 0.1-0.3). It is concluded that the relatives and friends of respondents who consumed tobacco would vary with respect to the type of school. Furthermore, it can be explored that youths can easily be entrapped in smoking if they get exposure to smoking. Above result reveals that around two-third of adolescents' relatives and friends were already indulged in smoking related activities. A study also reveals strong influences of parental socioeconomic status and their genetic makeup on tobacco and alcohol consumption practice of their children (Cleveland et.al., 2017). 
The table further reveals that a bit higher percent of respondents from private schools $(23.5 \%)$ consumed tobacco compared to those from community schools (22.4\%). But chi-square test shows no significant difference (Chi value= $0.034, \mathrm{df}=1$ and $\mathrm{P}$ value $0.869>0.05$ ) between these two variables. It can further be explained that the use of tobacco products does not get affected by the type of school. Similarly, among the tobacco users, 44.4 percent of them consumed cigarette (41.8 percent from community and 48.4 percent from private schools), followed by Panparag (25\%) and Gutkha (11.2\%). This result seems to be higher than the results revealed by NDHS. NDHS-2016 highlights that 16 percent adolescents of 15- 19 years age group consumed tobacco (MoH; New ERA; and ICF, 2017), compared to 20 percent in $2011(\mathrm{MoH}$; New ERA; and ICF, 2012). Similarly, 19.5 percent adolescents consumed tobacco and its products in USA (Clements\& Rivera, 2013) whereas 22.6 percent high school adolescents consumed tobacco in the UK (McKenzie et al., 2005).

As regards the frequency of using tobacco products, 47.1 percent respondents consumed tobacco just for taste (experimentation) followed by occasional users (25.5\%) and special function users (25.5\%). Only 2 percent of them consumed tobacco on regular basis. No respondent from private school consumed tobacco on regular basis. But, almost equal figure of students from both private and community schools consumed tobacco only in special functions like festivals, birthday treat and New Year eves.

Table 1 also demonstrates the age of first time to initiate tobacco consumption practice among community and private school students. Students from both types of schools started consuming tobacco before the age of 10 years. Whereas 58.8 percent were belonged to $10-15$ age group followed by 15 and above (33.3\%), and below $10(7.8 \%)$. The median age of initiating tobacco among community school students was 14 years compared to 15 years in private schools. Furthermore, t-test shows no significant difference (t-value $=0.013$, $\mathrm{df}=49$, and $\mathrm{P}$ value $=0.990$ in which $\mathrm{P}>$ 0.05 ) between first age to consuming tobacco products and type of school. A study conducted in the USA reveals that 10.7 percent of high school students smoke cigarette by the age of 13. Smoking initiation was higher for males compared to females (Clements \& Rivera, 2013). It shows that most of the adolescents start consuming tobacco as they enter the middle age of adolescence period.

Similarly, it is also revealed from table 1 that near to three-fourth $(74.5 \%)$ of the tobacco users tried to quit smoking; and the population of these respondents consist of 78.1 percent and 68.4 percent from community and private schools respectively. However, there is a narrow variation between community and private schools' data, as there is no significant difference (chi value $=0.591, \mathrm{df}=1$, and $\mathrm{p}$ value $0.515>0.05$ ) between these two variables (type of school and efforts to quit smoking habit). It means that there is no relation between the efforts to quit smoking habit and the type of school. However, it can be discussed that three-fourth of tobacco users tried to quit their smoking habit, but they could not give up. According to PRECEDE-PROCEED model of health promotion (Green \& Kreuter, 2005), people cannot change their ill behaviour in spite of having strong predisposing factors unless they get favourable enabling and reinforcing factors that support to change their behaviour.

\section{Factors influencing tobacco consumption}

Several factors have been identified as the reinforcing factors for tobacco consumption. These include tobacco industry advertising and promotion, easy access to tobacco products, and low price (McKenzie et. al., 2005). Peer pressure and smoking habits of parents and 
siblings are major contributing factors that influence the youths for smoking (Paudel, 2005). The Turkish study undertaken by Erbaydar (2012) showed that youths who were exposed to cigarette advertisement were 1.19 times more likely to experiment and 1.18 times more likely to continue smoking than those who were not exposed to such advertisements. Table 2 below demonstrates the factors influencing tobacco consumption behaviour among the high schools adolescents.

Table 2. Factors influencing tobacco consumption among adolescents

\begin{tabular}{lllllll}
\hline \multirow{2}{*}{ Influencing Factors } & \multicolumn{7}{c}{ School Type } \\
\cline { 2 - 7 } & \multicolumn{1}{c}{ Community } & Private & \multicolumn{3}{c}{ Total } \\
\cline { 2 - 7 } & $\mathrm{N}$ & $\%$ & $\mathrm{~N}$ & $\%$ & $\mathrm{~N}$ & $\%$ \\
\hline Peer pressure & 13 & 40.6 & 3 & 15.8 & 16 & 31.4 \\
Parent's influence & 2 & 6.2 & 1 & 5.3 & 3 & 5.9 \\
Cultural tradition & 0 & 0.0 & 2 & 10.5 & 2 & 3.9 \\
Media exposure & 1 & 3.1 & 1 & 5.3 & 2 & 3.9 \\
Experimentation & 14 & 43.8 & 12 & 63.2 & 26 & 51.0 \\
Influenced from smokers & 1 & 3.1 & 0 & 0.0 & 1 & 2.0 \\
Influenced from seniors & 1 & 3.1 & 0 & 0.0 & 1 & 2.0 \\
\multicolumn{1}{c}{ Total } & 32 & 100.0 & 19 & 100.0 & 51 & 100.0 \\
\hline
\end{tabular}

It is revealed from table 2 that 43.8 percent adolescents from community and 63.2 percent from private schools reported that they were influenced to consume tobacco just for experimentation rather than anything else. About one-third (31.4 percent) of them were influenced due to peer pressure which is 5.3 times more likely to consume tobacco than parental influence, and 8 times greater than cultural tradition and media exposure. Meanwhile, the study also reveals that in the case of students whose friends and relatives were ever smokers, they were 4 times more likely to be exposed to tobacco consumption behaviour than those whose friends and relatives were non smokers. However, raw data show a narrow difference between them, there is no significant difference $(\mathrm{Chi}$ value $=7.939$, $\mathrm{df}=6$, and $\mathrm{p}$ value $0.243>0.05$ ) between the type of school and influencing factors for tobacco consumption behaviour.

Peer pressure remains the second strong reinforcing factor for consuming tobacco products. Similar findings were extracted by Green (2002) who demonstrated that almost
90 percent of teen-age smokers in the United States acknowledge at least one of their four best friends who smoke on a regular basis while only 33 percent of nonsmokers had best friends who were smokers. Paudel (2005) also claims that peer pressure and smoking habit of parents and older siblings are major reinforcing factors for early smoking habit.

It can further be discussed that adolescents are vulnerable group to consuming tobacco and its products due to having the curiosity to taste tobacco and its products as well as due to the influence of unhealthy companies. An evidence based study in the USA concludes that, compared with non-smokers, early smokers are at higher risk of low academic achievement and behavioural problems at school and still there is more chance of their drop out from school (Suhrcke \& Nieves, 2011).

\section{Conclusion}

Tobacco consumption and health promotion have deeper interrelationship with each other. The findings from this study reflect that modest figure of high school adolescents afflict to 
tobacco consumption behaviour. However, most of the tobacco users consumed tobacco just for entertainment and experimentation; surprisingly they could not give up such habit. This may lead them towards becoming the habitual smokers, which becomes more painful to them in their upcoming life since habitual smoking results in fatal health condition. Various factors are associated with consuming tobacco amongst which peer pressure, parental and relatives' influence, and media exposure remain the significant ones. Now, monitoring high-risk behaviors of adolescents, announcing tobaccofree public places, informing adolescents about misinformation on tobacco use that is glamorized in the tobacco promotional proactive advertisements, making adolescents' parents aware against the consequences of smoking in front of their children, will be the helpful steps to minimize tobacco consumption practices among schooling youths.

\section{Acknowledgements}

This article is the revised version of the mini-research undertaken with the support of University Grants Commission (UGC) in 2015. I would like to acknowledge UGC for providing me with the financial grant to complete this study. Similarly, I extend my sincere gratitude to all research participants who provided the invaluable information required to complete this study. All the people who put their efforts to make this article in this kind also deserve heartfelt thanks.

\section{REFERENCES}

Clements, N. K., \& Rivera, C. (2013). The Epidemiology of Adolescent. In W. T. O'Donohue, L. W. Tolle, \& L. T. BenutoHandbook of Adolescnets Helath Psychology (pp. 77-92). London: Springer New York Heidelberg Dordrecht

Cleveland, H. H., Wiebe, R. P., \& Rowe, D. C. (2017). Sources of exposure to smoking and drinking friends among adolescents: a behavioral-genetic evaluation. Biosocial Theories of Crime, 253.

Erbaydar, T., et al. (2012). Smoking pattern of youth in Turkey. Istanbul: Marmara University.

Green, D.E. (2002). Teenage tobacco consumption: Immediate and long term patterns. Washington DC, US Government Printing Office.

McKenzie, J.F., Pinger, R.R. \& Kotecki, J.E (2005). An introduction to community health (5th Edition) Boston: Allyn and Bacon.

Ministry of Health, Nepal; New ERA; and ICF. (2012). Nepal demographic and health survey 2016. Kathmandu: Ministry of Health.

Mujis, D. (2004). Doing quantitative research in education with SPSS. London. Thousand Oaks. New Delhi: Sage Publication.

Pande, B.R., Karki, Y.B., \& Pant, K.D. (2000). A study on tobacco economics in Nepal. WHO/ SEARO.

Paudel, D. (2005). Tobacco use among adolescent students in secondary schools of Pokhara sub metropolitan city of Nepal. The Centers for Disease Control and Prevention. GYTS.

Sinha, D.N. et al. (2006). Linking Global Youth Tobacco Survey data to the WHO framework convention on tobacco control: the case for India. Indian J Public Health. 50:76-89.

Sinha, D.N. (2002.) Report on the results of the global youth tobacco survey in Uttar Pradesh, Indi. Available from: http://www.searo.who. int/retrieved dated on $10^{\text {th }}$ Jan. 2014.

Suhrcke, M. \& Nieves, C. P. (2011). The impact of health and health behaviours on educational outcomes in high-income countries: A review of the evidence. Copenhagen, WHO Regional Office for Europe.

WHO. (2000). Addressing the worldwide tobacco epidemic through effective evidence-based treatment. Minnesota: USA. Tobacco Free Initiative, WHO.

WHO.(2014). Global youth tobacco survey, tobacco use among youths; A crosscountry comparison, Tobacco control.Authors . 